Article

\title{
Enhanced Hydrolysis of Cellulose in Ionic Liquid Using Mesoporous ZSM-5
}

\author{
Tianlu Chen ${ }^{1}$ (D), Chunrong Xiong ${ }^{2, *}$ and Yousheng Tao ${ }^{1, *}$ \\ 1 CAS Key Laboratory of Design and Assembly of Functional Nanostructures, Haixi Institutes, \\ Chinese Academy of Sciences (CAS), Fuzhou 350002, China; chentianlu@fjirsm.ac.cn \\ 2 College of Materials and Chemical Engineering, Hainan University, Haikou 570228, China \\ * Correspondence: bearcr_82@hotmail.com (C.X.); taoys@tom.com (Y.T.); Tel.: +86-591-63173107 (Y.T.)
}

Received: 31 October 2017; Accepted: 30 January 2018; Published: 27 February 2018

\begin{abstract}
Mesoporous ZSM-5 prepared by alkaline treatment was demonstrated as an efficient catalyst for the cellulose hydrolysis in ionic liquid (IL), affording a high yield of reducing sugar. It was demonstrated that mesoporous $\mathrm{ZSM}-5\left(\mathrm{SiO}_{2} / \mathrm{Al}_{2} \mathrm{O}_{3}=38\right)$ had $76.2 \%$ cellulose conversion and $49.6 \%$ yield of total reducing sugar (TRS). In comparison, the conventional ZSM-5 had a mere $41.3 \%$ cellulose conversion with $33.2 \%$ yield of TRS. The results indicated that the important role of mesopores in zeolites in elevating the TRS yield may be due to the diffusional alleviation of cellulose macromolecules. The effects of reaction time, temperature, and the ratio of catalyst to cellulose were investigated for optimal reaction conditions. It was found that IL could enter the inner channel of mesoporous ZSM-5 to promote the generation of $\mathrm{H}^{+}$from Brönsted acid sites, which facilitated hydrolysis. Moreover, the mesoporous ZSM-5 showed excellent reusability for catalytic cycles by means of calcination of the used one, promising for its practical applications in the hydrolysis of cellulose.
\end{abstract}

Keywords: mesopores; zeolites; ZSM-5; cellulose; catalysis; hydrolysis; ionic liquids

\section{Introduction}

The conversion of renewable biomass into useful chemicals is of importance in green and sustainable chemistry [1-3]. Cellulose is the most abundant source of biomass. Its robust structure, composed of 1,4- $\beta$-glycosidic bonds of D-anhydroglucopyranose, has impeded its wide utilization $[4,5]$. Nevertheless, breakage of $1,4-\beta$-glycosidic bonds by acids to hydrolyze cellulose into reducing sugar is a key process for the use of cellulose.

Efforts with mineral acids [6], enzymes [7], and supercritical water [8] have been devoted to cellulose hydrolysis. However, there are distinct drawbacks in these traditional methods, such as the corrosion of reactors, the high cost of enzymes, harsh reaction conditions, and difficult separation of the products $[9,10]$. On the contrary, solid acid catalysts have advantages of easy product separation, recyclability, and little damage of the reactor [11-16].

Due to containing both Lewis and Brönsted acid sites, zeolites have applications in the hydrolysis of cellulose [17-21]. Onda et al. [21] reported different H-form zeolites, such as H-mordenite, H-beta, and H-ZSM- 5 for the hydrolysis of cellulose in water. Compared to sulfonated activated carbon, the product yield over H-ZSM- 5 was low due to the small channels and cavities of zeolites, which imposed diffusional limitations on reactions. In order to improve the catalytic activities of zeolites under milder conditions, Cai et al. [17] proposed an approach by using an ionic liquid as the solvent to increase the solubility of cellulose. In this manner, the contact between cellulose and zeolites was improved. It became clear that the pore sizes and the acid amount of zeolites were critical for the high hydrolysis efficiency of cellulose. 
Mesoporous zeolites have been applied in industry for fluid catalytic cracking and hydrocracking [22,23]. In recent years, mesoporous zeolites also have attracted a great interest in biomass hydrolysis owing to their high thermal stability and the diffusional alleviation of large reactant molecules [24-26]. Zhou et al. [25] used the hierarchical H-USY zeolites prepared by oxalic acid treatment for the hydrolysis of hemicelluloses. The yield of total reducing sugars (TRS) increased remarkably over H-USY of mesopores/macropores compared with conventional H-USY under the same reaction conditions. They also investigated sulfonated hierarchical H-USY for microcrystalline cellulose hydrolysis but achieved a mere $15.8 \%$ yield of TRS [26]. This suggests that although the mesopores of zeolites are favorable for the higher yield of sugars in hemicelluloses hydrolysis, it is a challenge to develop efficient catalytic hydrolysis of cellulose with zeolites. In this work, mesoporous ZSM-5 prepared with alkaline treatment was applied in the hydrolysis of cellulose in an ionic liquid of 1-butyl-3-methyl imidazolium chloride $([\mathrm{BMIm}] \mathrm{Cl})$. We investigated the reaction conditions and catalyst reusability and demonstrated the role of mesopores in elevating the yield of TRS.

\section{Experimental}

\subsection{Materials}

Microcrystalline cellulose with an average particle size of $25 \mu \mathrm{m}$ and the ionic liquid of 1-butyl-3-methylimidazolium chloride ([BMIm] $\mathrm{Cl})$ were purchased from Adamas Organics, Shanghai, China. ZSM-5 $\left(\mathrm{SiO}_{2} / \mathrm{Al}_{2} \mathrm{O}_{3}=38\right)$ and $\mathrm{ZSM}-5\left(\mathrm{SiO}_{2} / \mathrm{Al}_{2} \mathrm{O}_{3}=100\right)$ were supplied by XFNANO Materials Tech Co., Ltd., Nanjing, China and Acros Organics, Geel, Belgium, respectively.

\subsection{Characterization Methods}

The powder X-ray diffraction (XRD) patterns were acquired on a MiniFlex II X-ray diffractometer (Rigaku Co., Salem, NH, USA) using $\mathrm{Cu} K \alpha(\lambda=0.154050 \mathrm{~nm})$ radiation. $\mathrm{N}_{2}$ adsorption and desorption isotherms on samples were measured at $77 \mathrm{~K}$ using a sorptometer ASAP2020 (Micromeritics, Norcross, GA, USA). Samples were evacuated at $10^{-4} \mathrm{~Pa}$ and $393 \mathrm{~K}$ for $2 \mathrm{~h}$ before the measurement. Al concentrations in the zeolites were determined by ICP-AES in an Ultima2 spectrometer (HORIBA JobinYvon, Paris, France). The Brönsted acid sites in the catalysts were measured by the titration method as follows: $20 \mathrm{~mL}$ of $0.01 \mathrm{M}$ sodium hydroxide aqueous solution was added to $0.04 \mathrm{~g}$ of catalyst. The mixture was stirred for $2 \mathrm{~h}$ at room temperature. After centrifugal separation, the supernatant solution was titrated with a $0.01 \mathrm{M}$ hydrochloric acid aqueous solution using phenolphthalein [21]. Elemental analysis of ionic liquid treated zeolite was done using a Viario MICRO elemental analyzer (Elementar, Langenselbold, Germany).

\subsection{Preparation of Mesoporous ZSM-5}

Mesorporous ZSM-5 was prepared with alkaline treatment. In a typical procedure, the parent ZSM- 5 zeolites were treated in $0.2 \mathrm{M}$ aqueous sodium hydroxide solutions at $338 \mathrm{~K}$ for different periods of time. The remaining solid product was filtered, washed, and dried at $373 \mathrm{~K}$ for $12 \mathrm{~h}$. The alkaline-treated samples were converted into the $\mathrm{H}$-forms by ion exchanged twice in a $1.0 \mathrm{M}$ $\mathrm{NH}_{4} \mathrm{NO}_{3}$ solution at $353 \mathrm{~K}$ for $4 \mathrm{~h}$, followed by calcination at $823 \mathrm{~K}$ for $5 \mathrm{~h}$. The samples were denoted as H-Z-T, where T represented the time of alkaline treatment.

\subsection{Catalytic Reactions}

The hydrolysis of cellulose was performed in a sealed glass tube using the established procedures $[17,24]$. Fifty milligrams of cellulose was added portion wise to $1.0 \mathrm{~g}$ of [BMIm]Cl at $373 \mathrm{~K}$. The mixture was stirred until a yellowish solution formed. To this solution were quickly added $0.2 \mathrm{~mL}$ of $\mathrm{H}_{2} \mathrm{O}$ and $50.0 \mathrm{mg}$ of solid acid catalyst. The reaction mixture was taken out, weighed, quenched in ice water, and then centrifuged. The volumes of the samples were measured and the 
TRS of the products was analyzed. To test reusability of mesoporous zeolites, the solid residue was calcinated at $823 \mathrm{~K}$ for $5 \mathrm{~h}$ before use in the subsequent runs.

\subsection{Analysis Methods}

The conversion of cellulose was determined based on the differences in weight of cellulose before and after the reaction. The TRS of the products was analyzed using an established method [27]. The mixture containing $1.5 \mathrm{~mL} 3,5$-dinitrosalicylic acid reagent and $0.2 \mathrm{~mL}$ samples was heated at $373 \mathrm{~K}$ for $5 \mathrm{~min}$, then cooled to room temperature and diluted to $10 \mathrm{~mL}$. The absorbance of the mixture was measured at $540 \mathrm{~nm}$ using a 1100 UV-VIS spectrophotometer (MAPADA Instruments Co. Ltd., Shanghai, China). The TRS concentration of the products was determined by using the adsorption factor of standard glucose solution. The mass of TRS and the yield of TRS from cellulose were calculated as follows:

$$
\begin{gathered}
M_{\mathrm{T}}=\text { TRS concentration }(\mathrm{mg} / \mathrm{mL}) \times 10(\mathrm{~mL}) \times(\mathrm{V} / 0.2) \times\left(\mathrm{M}_{0} / \mathrm{M}_{1}\right) \\
\text { TRS yield }=M_{\mathrm{T}} / \mathrm{M} \times 100 \%
\end{gathered}
$$

where $M_{\mathrm{T}}$ is the mass of TRS. $\mathrm{V}$ is the volume of the samples. $\mathrm{M}_{0}$ is the total mass of the reaction solution. $\mathrm{M}_{1}$ and $\mathrm{M}$ are the masses of samples and cellulose initially loaded for the reaction, respectively.

\section{Result and Discussion}

\subsection{Chemical and Pore Structures of the Samples}

Alkaline treatment of ZSM-5 can create mesopores through the selective extraction of framework Si atoms, meanwhile, preserving its hydrothermal stability and acidity to some extent [28-30]. The XRD patterns of the parent ZSM-5 and the alkaline-treated ZSM- 5 are shown in Figure 1 . The basic fingerprints of zeolite after alkaline treatment were maintained, suggesting that the crystalline phases of zeolite did not change upon the alkaline treatment. However, the crystallinity of the samples decreased with the increasing period of alkaline treatment because the removal of Si from the framework of the zeolite formed large pores, as well as defect domains [31]. The FT-IR spectra of the parent ZSM-5 and the alkaline-treated ZSM-5 were also studied. The absorption bands of them were identical with respect not only to the band positions, but also to the peak intensity, suggesting the surface chemistry in alkaline treated ZSM-5 zeolites has remained virtually unchanged.

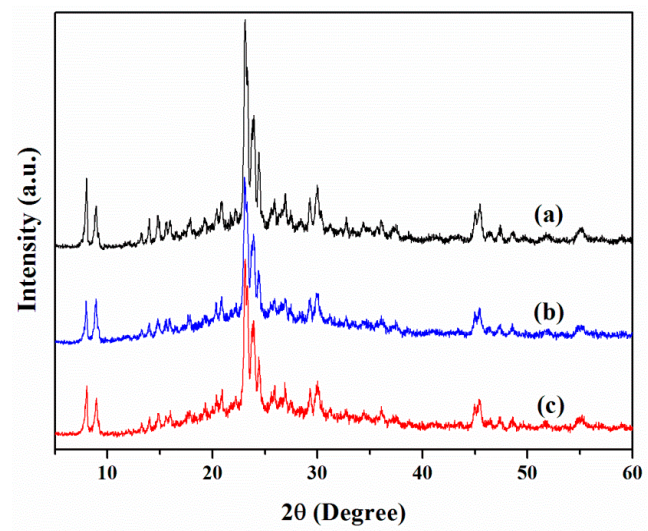

Figure 1. XRD patterns of the alkaline-treated ZSM-5 and the parent ZSM-5 zeolites: (a) H-Z-0; (b) H-Z-20; and (c) H-Z-30.

Figure 2 shows the $\mathrm{N}_{2}$ adsorption/desorption isotherms at $77 \mathrm{~K}$ on the alkaline-treated ZSM- 5 and the parent ZSM-5. Compared with that of parent zeolites, the isotherms of alkaline-treated zeolites 
had increases in uptakes and changes in the shapes of hysteresis loops extending from $\mathrm{P} / \mathrm{P}_{0}=0.4$ to $\sim 1$, indicating that the mesopores had been created upon the alkaline treatments. The mesopores with pore sizes of 2-25 $\mathrm{nm}$ were gradually developed with the increase of the treatment period. Both the total pore volume and mesopore volume increased after the alkaline treatments, while the micropore volume was almost maintained, as displayed in Table 1 . It was known that the amount of $\mathrm{Al}$ atoms was proportional to the amount of Brönsted acid sites [32]. The acid sites of H-Z-0, H-Z-20, and $\mathrm{H}-\mathrm{Z}-30$ zeolites were $0.43 \mathrm{mmol} / \mathrm{g}, 0.45 \mathrm{mmol} / \mathrm{g}$, and $0.51 \mathrm{mmol} / \mathrm{g}$, respectively. The higher acidity of mesoporous ZSM-5 in comparison with parent ZSM-5 was attributed to a decrease in the $\mathrm{Si} / \mathrm{Al}$ ratio by the removal of framework Si [24].

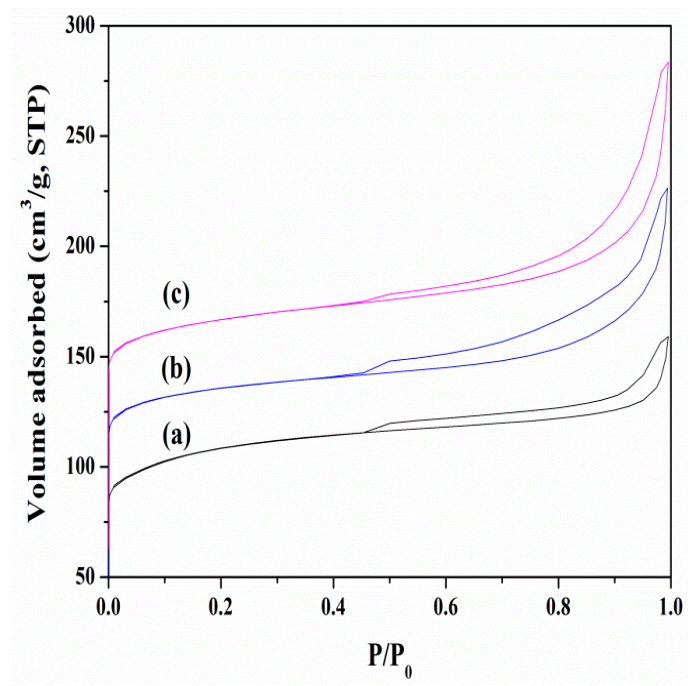

Figure 2. Adsorption/desorption isotherms of nitrogen at $77 \mathrm{~K}$ on the alkaline-treated ZSM- 5 and the parent ZSM-5 zeolites: (a) H-Z-0; (b) H-Z-20; and (c) H-Z-30. For clarity the isotherms of H-Z-20 and $\mathrm{H}-\mathrm{Z}-30$ have been shifted upward by $50 \mathrm{~cm}^{3} / \mathrm{g}$ and $100 \mathrm{~cm}^{3} / \mathrm{g}$, respectively.

Table 1. The amount of $\mathrm{Al}$ atoms, pore structure parameters and the acid sites of the parent and mesoporous ZSM-5 zeolites.

\begin{tabular}{ccccccc}
\hline \multirow{2}{*}{ Catalyst Sample } & \multirow{2}{*}{ Al (wt \%) } & \multirow{2}{*}{ BET Surface Area $\left(\mathbf{m}^{2} / \mathbf{g}\right)$} & \multicolumn{3}{c}{ Pore Volume $\left(\mathbf{c m}^{\mathbf{3}} \mathbf{g}\right)$} & \multirow{2}{*}{ Acid Sites $(\mathbf{m m o l} / \mathbf{g})$} \\
\cline { 4 - 6 } & & & $\mathbf{V}_{\text {meso }}$ & $\mathbf{V}_{\text {micro }}$ & $\mathbf{V}_{\text {total }}$ & \\
H-Z-0 & 1.95 & 365 & 0.13 & 0.13 & 0.26 & 0.43 \\
H-Z-20 & 2.03 & 340 & 0.18 & 0.13 & 0.31 & 0.45 \\
H-Z-30 & 2.36 & 350 & 0.22 & 0.12 & 0.34 & 0.51 \\
\hline
\end{tabular}

\subsection{Catalytic Performance of the Samples}

\subsubsection{Hydrolysis of Cellulose}

Pore structures and acidity are the important factors affecting the performance of the catalysts for the cellulose hydrolysis. Figures 3 and 4 show the hydrolysis of cellulose in [BMImCl] catalyzed by the alkaline-treated ZSM- 5 and the parent ZSM- 5 zeolites with $\mathrm{SiO}_{2} / \mathrm{Al}_{2} \mathrm{O}_{3}$ ratios of 38 and 100 , respectively. As a reference reaction, cellulose hydrolysis in IL without catalyst had a TRS yield of $18.2 \%$. The cellulose can dissolve in IL to form a homogeneous solution. The dissociated $\mathrm{Cl}^{-}$and the electron-rich aromatic $\pi$ system of [BMIm] $]^{+}$in [BMIm] $\mathrm{Cl}$ should weaken the glycosidic linkage of cellulose to facilitate hydrolysis $[33,34]$.

When the parent ZSM-5 $\left(\mathrm{SiO}_{2} / \mathrm{Al}_{2} \mathrm{O}_{3}=38\right)$ was used as a catalyst to hydrolyze cellulose at $403 \mathrm{~K}$ for $2 \mathrm{~h}$, it gave the cellulose conversion of $41.3 \%$ with a TRS yield of $33.2 \%$. In contrast, the corresponding values increased remarkably with the use of the alkaline-treated ZSM-5. 
Mesopores made a large number of the acid sites of zeolites accessible to the $\beta$-glucosidic bonds, promoting the mass transfer of cellulose and reducing sugars in a timely manner [35]. The mesopores also facilitated the $[\mathrm{BMIm}] \mathrm{Cl}$ entering the inner spaces of the zeolites. Ion-exchange involving [BMIM] ${ }^{+}$ and $\mathrm{H}^{+}$species promoted the generation of $\mathrm{H}^{+}$from Brönsted acid sites of H-form zeolites [17,36]. The higher acidity or the larger amount of Brönsted acid of mesoporous ZSM- 5 than that of parent ZSM-5 due to its lower Si / Al ratio also contributed to higher activity in the cellulose hydrolysis [37,38]. H-Z-30 zeolite had excellent catalytic performance, with a maximum of $76.2 \%$ cellulose conversion and $49.6 \%$ TRS yield. The large amount of mesopores of H-Z-30 zeolite facilitated the reaction products to diffuse out the catalyst instead of their further conversion to byproducts.

Similarly, hydrolysis of cellulose was studied using parent ZSM-5 and mesoporous ZSM-5 zeolites with the ratio of $\mathrm{Si} / \mathrm{Al}\left(\mathrm{SiO}_{2} / \mathrm{Al}_{2} \mathrm{O}_{3}=100\right)$. The yield of TRS increased to $34.4 \%$ over mesoporous H-Z-30 (100) in comparison with $26.4 \%$ yield of TRS over H-Z-0 (100). However, it was found that the TRS yield decreased with the increase of the $\mathrm{Si} / \mathrm{Al}$ ratio due to the fewer acid sites.

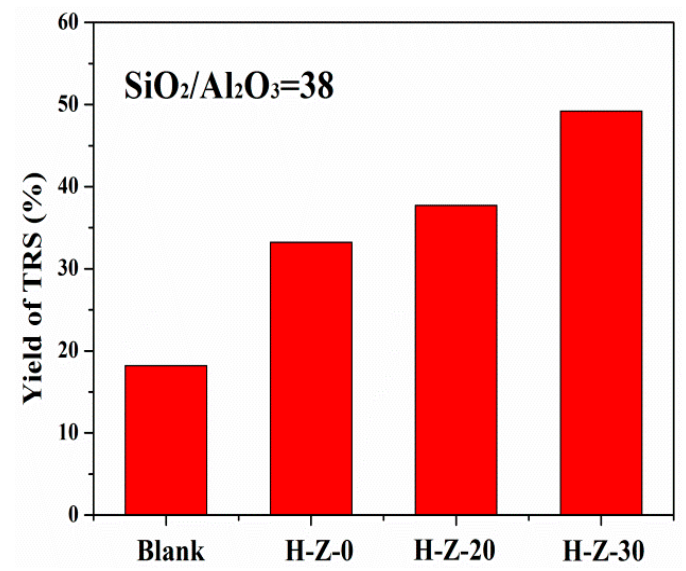

Figure 3. Hydrolysis of cellulose catalyzed by the alkaline-treated ZSM- 5 and the parent ZSM- 5 zeolites with $\mathrm{SiO}_{2} / \mathrm{Al}_{2} \mathrm{O}_{3}$ ratio of 38. Reaction conditions: [BMIm]Cl (1.0 g), cellulose (50.0 mg), catalyst (50.0 mg), water $(0.2 \mathrm{~mL})$, at $403 \mathrm{~K}$ and $2 \mathrm{~h}$.

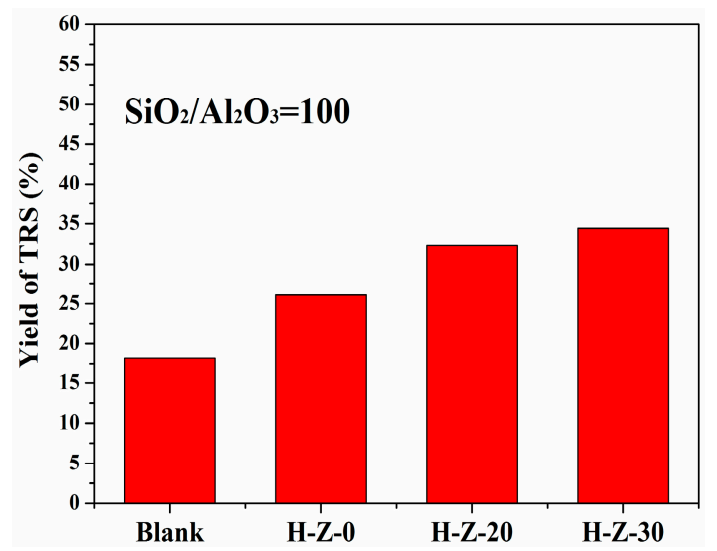

Figure 4. Hydrolysis of cellulose catalyzed by the alkaline-treated ZSM- 5 and the parent ZSM- 5 zeolites with $\mathrm{SiO}_{2} / \mathrm{Al}_{2} \mathrm{O}_{3}$ ratio of 100 . Reaction conditions: [BMIm] Cl (1.0 g), cellulose (50.0 mg), catalyst (50.0 mg), water $(0.2 \mathrm{~mL})$, at $403 \mathrm{~K}$ and $2 \mathrm{~h}$.

\subsubsection{Effect of Reaction Conditions on Cellulose Hydrolysis over H-Z-30}

The effect of reaction conditions such as reaction time, temperature, and the ratio of catalyst and cellulose on the catalytic performance of H-Z-30 were investigated in order to maximize the yield of TRS. The reaction time is important for the cellulose hydrolysis due to the fact that sugars 
can be further transformed to other byproducts, such as levulinic acid, 5-hydroxymethylfurfural (5-HMF), formic acid, and furfural [39]. The effect of reaction time of H-Z-30 on TRS yields was investigated at $403 \mathrm{~K}$. As shown in Figure $5 \mathrm{a}$, with the increase of reaction time, the yield of TRS increased obviously at the initial stage. After reaching the maximum yield of $49.6 \%$ in $2 \mathrm{~h}$, the TRS yield slowly reduced from $2.5 \mathrm{~h}$ to $3.5 \mathrm{~h}$ owing to the conversion of the formed sugars. Figure $5 \mathrm{~b}$ presents the effect of reaction temperature on TRS yields. The yield of TRS increased from $20.1 \%$ to $49.6 \%$ as the temperature was elevated from $383 \mathrm{~K}$ to $403 \mathrm{~K}$. Subsequently, the TRS yield decreased with the increasing temperature because the produced sugars decomposed to 5-HMF easily at high temperature $[18,24,40]$. After the reaction the solid became black due to insoluble side-products containing humins at $423 \mathrm{~K}$. Figure $5 \mathrm{c}$ demonstrates the effects of the weight ratio of catalyst to cellulose on the TRS yield. The TRS yield increased and then decreased with the increase of the catalyst usage. The highest yield of TRS (52.6\%) was obtained at the weight ratio of catalyst to cellulose being 1.5. After that, catalysts had redundant acid sites which accelerated the transformation of the produced sugars to other byproducts.
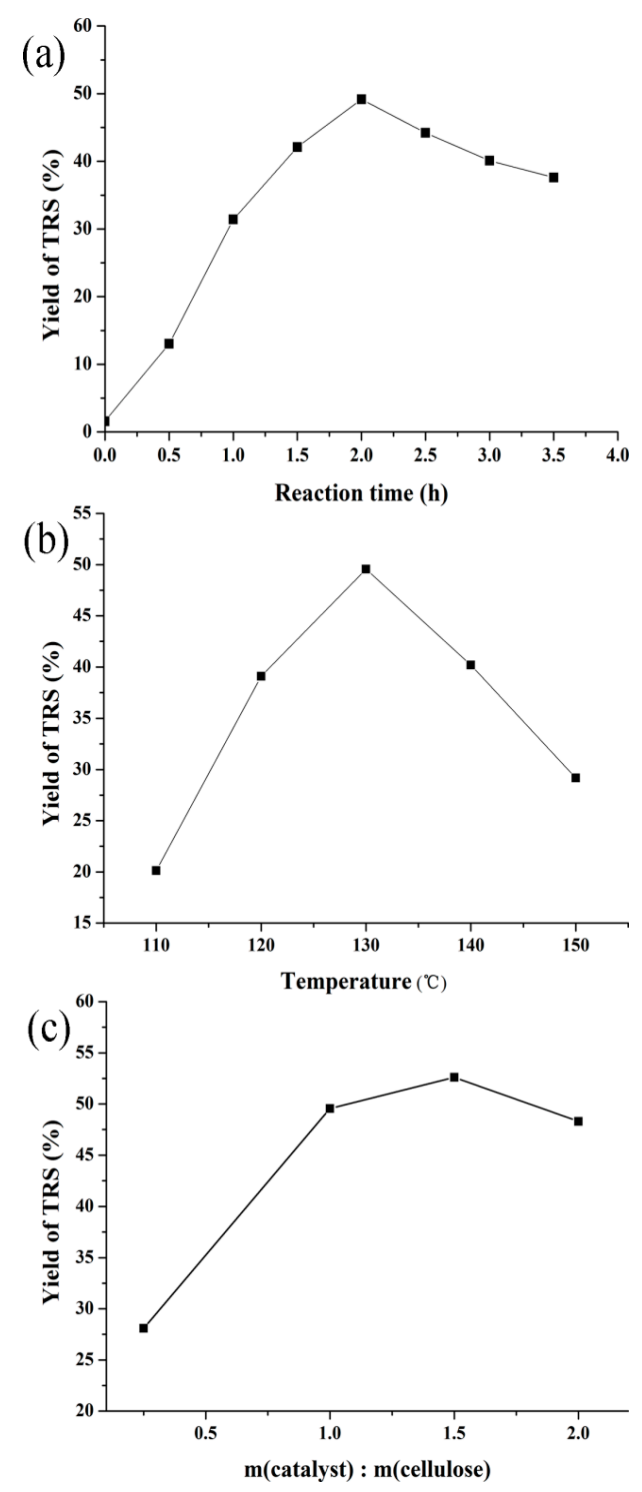

Figure 5. The effect of reaction time (a); temperature (b); and weight ratio of catalysts to cellulose (c) on TRS yields over H-Z-30. Reaction conditions: [BMIm]Cl (1.0 g), water $(0.2 \mathrm{~mL})$. 


\subsubsection{The Role of Mesopores in Zeolites for Ionic Liquid}

Previous work showed that the IL could enter the inner channel of $\mathrm{H}$-form zeolites to promote cellulose hydrolysis $[9,17,33,40]$. In order to illustrate the mutual interactions of mesoporous ZSM-5 and IL during the hydrolysis process, IL-treated H-Z-30 was characterized by means of XRD, as shown in Figure 6. The XRD patterns of fresh H-Z-30 (a), the IL-treated H-Z-30 (b), and the recovered H-Z-30 after calcinations demonstrated that the framework structure of $\mathrm{H}-\mathrm{Z}-30$ was particularly stable in IL. However, the peak at $24.4^{\circ}$ of IL-treated H-Z-30 shifted about $0.09^{\circ}$ to lower angle value with respect to fresh catalyst, indicating that $[\mathrm{BMIm}] \mathrm{Cl}$ entered the pore of $\mathrm{H}-\mathrm{Z}-30$ due to the dilatation effect. The element analysis of IL-treated H-Z-30 indicated $\mathrm{N}$ and $\mathrm{C}$ mass contents of $1.68 \%$ and $6.49 \%$ (the N/C molar ratio was 1:4), matching with the N/C molar ratio in $[\mathrm{BMIm}]^{+}\left(\left[\mathrm{C}_{8} \mathrm{H}_{15} \mathrm{~N}_{2}\right]^{+}\right)$. The $\mathrm{N}_{2}$ adsorption results further demonstrated that IL entered and occupied some nanospace in $\mathrm{H}-\mathrm{Z}-30$. The BET surface area, mesopore volume, and total pore volume of fresh H-Z-30 were determined to be $350 \mathrm{~m}^{2} / \mathrm{g}, 0.22 \mathrm{~cm}^{3} / \mathrm{g}$, and $0.34 \mathrm{~cm}^{3} / \mathrm{g}$, respectively (Table 1). Comparatively, the corresponding values of IL-treated H-Z-30 decreased to $70 \mathrm{~m}^{2} / \mathrm{g}, 0.19 \mathrm{~cm}^{3} / \mathrm{g}$, and $0.20 \mathrm{~cm}^{3} / \mathrm{g}$, respectively. After calcinations, the values recovered to $350 \mathrm{~m}^{2} / \mathrm{g}, 0.22 \mathrm{~cm}^{3} / \mathrm{g}$, and $0.34 \mathrm{~cm}^{3} / \mathrm{g}$, respectively. This suggested that the $\mathrm{IL}$ in the pores of $\mathrm{H}-\mathrm{Z}-30$ could be removed by calcination. Hence, the $[\mathrm{BMIm}]^{+}$entered the inner channels and caves of mesoporous ZSM- 5 and promoted the generation of $\mathrm{H}^{+}$from Brönsted acid sites via ion exchange to facilitate hydrolysis. The proposed reaction pathway of zeolite and [BMIm] $]^{+}$is shown in Figure 7.

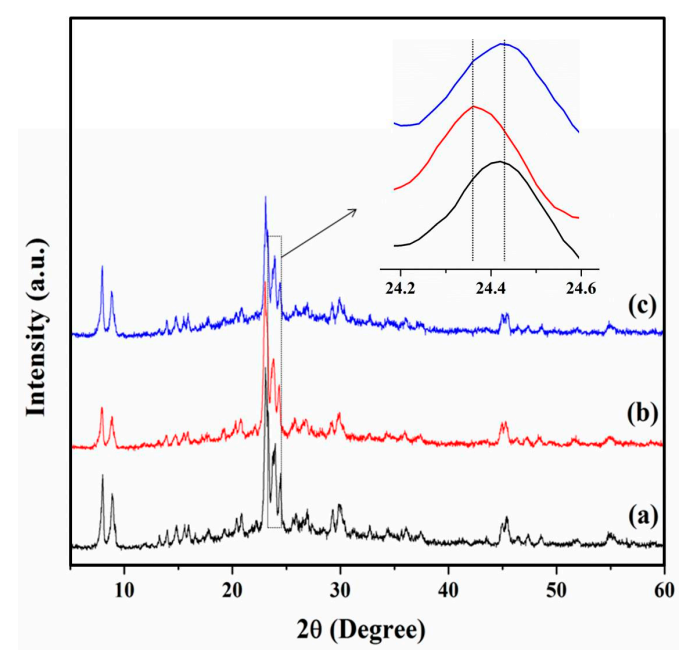

Figure 6. XRD patterns of H-Z-30 before and after IL-treatments. (a) H-Z-30; (b) IL-treated H-Z-30; and (c) samples of calcined IL-treated H-Z-30 at $823 \mathrm{~K}$ for $5 \mathrm{~h}$.

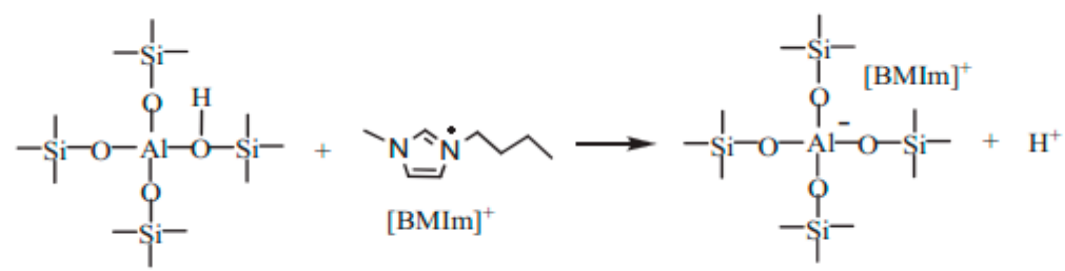

Figure 7. The proposed reaction pathway of zeolite and [BMIm] $]^{+}$.

\subsubsection{Catalytic Cycling of Mesoporous ZSM-5 in Cellulose Hydrolysis}

The catalytic activity and stability of zeolite were important for its practical applications in the hydrolysis of cellulose. After each reaction, H-Z-30 was separated for the calcination. After each cycle as well as calcination, the crystalline phases of mesoporous ZSM-5 were identical to the fresh one 
(Figure 8$)$ and the acidity sites remained $(0.49 \mathrm{mmol} / \mathrm{g})$. As shown in Figure 9, H-Z-30 was stable for three catalytic cycles, with a $41.3 \%$ yield of TRS.

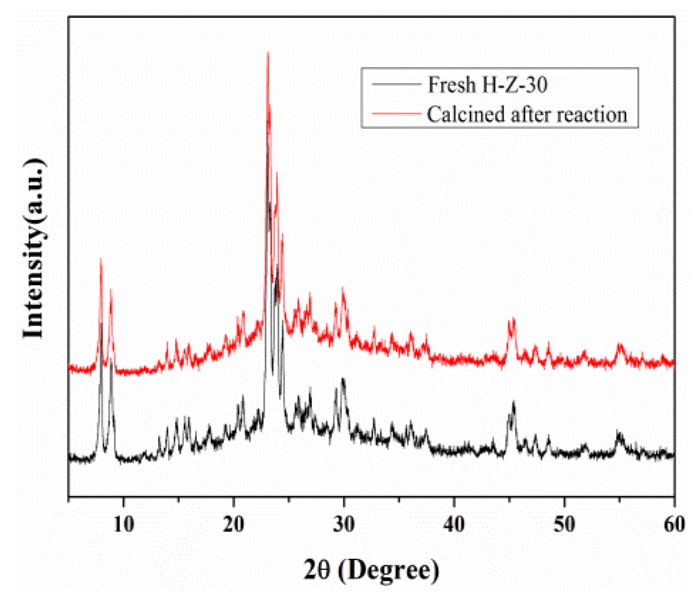

Figure 8. XRD patterns of fresh H-Z-30 and calcined H-Z-30 after the cellulose hydrolysis.

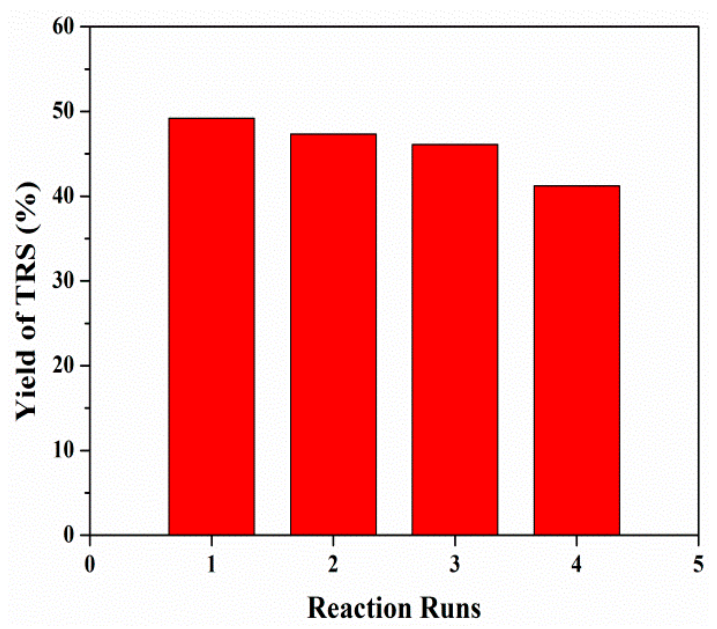

Figure 9. Yield of TRS vs. catalytic cycles of H-Z-30 in hydrolysis of cellulose. Reaction conditions: [BMIm]Cl (1.0 g), cellulose (50.0 mg), catalyst $(50.0 \mathrm{mg})$, water $(0.2 \mathrm{~mL})$, at $403 \mathrm{~K}$ and $2 \mathrm{~h}$.

\section{Conclusions}

Mesoporous ZSM-5 zeolites prepared by alkaline-treatment of parent zeolites almost preserved their acidity and stability. The samples were applied in catalytic hydrolysis of cellulose in an ionic liquid to afford reducing sugars. The mesopores played an important role in elevating the yield of TRS. The mesopores not only improved the accessibility of the acid sites, but might also facilitate the reaction products to diffuse out of the catalysts in a timely manner, restraining its further conversion to byproducts. The role of diffusion on the reaction progress needs to be illustrated in future work. Moreover, the mesopores made [BMIm] $]^{+}$enter the nanospaces of ZSM-5, promoting the generation of $\mathrm{H}^{+}$from Brönsted acid sites via ion exchange to facilitate hydrolysis. On the other hand, the higher acidity of mesoporous zeolites (the lower $\mathrm{Si} / \mathrm{Al}$ molar ratio) was also helpful for the hydrolysis of cellulose. Importantly, the mesoporous ZSM-5 showed excellent reusability for catalytic cycles, promising for its practical applications in the hydrolysis of cellulose.

Acknowledgments: This work was financially supported by the National Natural Science Foundation of China (21273236) and supported from Science and Technology Planning Projects of Fujian Province of China (2014H2008 and 2015I0008) and the Science and Technology Service Network Initiative (STS) Project of Fujian-CAS (2016T3036). 
Author Contributions: Tianlu Chen contributed to the experiments and the analysis of data, and wrote the initial draft. Chunrong Xiong had discussion and the analysis of data. Yousheng Tao designed the experiments and had the analysis of data, manuscript refinement and revision.

Conflicts of Interest: The authors declare no conflicts of interest.

\section{References}

1. Schmidt, L.D.; Dauenhauer, P.J. Chemical engineering: Hybrid routes to biofuels. Nature 2007, 447, 914-915. [CrossRef] [PubMed]

2. Corma, A.; Iborra, S.; Velty, A. Chemical routes for the transformation of biomass into chemicals. Chem. Rev. 2007, 107, 2411-2502. [CrossRef] [PubMed]

3. Alonso, D.M.; Bond, J.Q.; Dumesic, J.A. Catalytic conversion of biomass to biofuels. Green Chem. 2010, 12, 1493-1513. [CrossRef]

4. Jarvis, M. Chemistry: Cellulose stacks up. Nature 2003, 426, 611-612. [CrossRef] [PubMed]

5. Himmel, M.E.; Ding, S.Y.; Johnson, D.K.; Adney, W.S.; Nimlos, M.R.; Brady, J.W.; Foust, T.D. Biomass recalcitrance: Engineering plants and enzymes for biofuels production. Science 2007, 315, 804-807. [CrossRef] [PubMed]

6. Antonoplis, R.A.; Blanch, H.W.; Freitas, R.P.; Sciamanna, A.F.; Wilke, C.R. Production of sugars from wood using high-pressure hydrogen chloride. Biotechnol. Bioeng. 1983, 25, 2757-2773. [CrossRef] [PubMed]

7. Zhang, Y.H.P.; Lynd, L.R. Toward an aggregated understanding of enzymatic hydrolysis of cellulose: Noncomplexed cellulase systems. Biotechnol. Bioeng. 2004, 88, 797-824. [CrossRef] [PubMed]

8. Sasaki, M.; Fang, Z.; Fukushima, Y.; Adschiri, T.; Arai, K. Dissolution and hydrolysis of cellulose in subcritical and supercritical water. Ind. Eng. Chem. Res. 2000, 39, 2883-2890. [CrossRef]

9. Huang, Y.B.; Fu, Y. Hydrolysis of cellulose to glucose by solid acid catalysts. Green Chem. 2013, 15, $1095-1111$. [CrossRef]

10. Van de Vyver, S.; Geboers, J.; Jacobs, P.A.; Sels, B.F. Recent advances in the catalytic conversion of cellulose. ChemCatChem 2011, 3, 82-94. [CrossRef]

11. Shuai, L.; Pan, X. Hydrolysis of cellulose by cellulase-mimetic solid catalyst. Energy Environ. Sci. 2012, 5, 6889-6894. [CrossRef]

12. Suganuma, S.; Nakajima, K.; Kitano, M.; Yamaguchi, D.; Kato, H.; Hayashi, S.; Hara, M. Hydrolysis of cellulose by amorphous carbon bearing $\mathrm{SO}_{3} \mathrm{H}, \mathrm{COOH}$, and $\mathrm{OH}$ groups. J. Am. Chem. Soc. 2008, 130, 12787-12793. [CrossRef] [PubMed]

13. Shimizu, K.; Furukawa, H.; Kobayashi, N.; Itaya, Y.; Satsuma, A. Effects of Brønsted and Lewis acidities on activity and selectivity of heteropolyacid-based catalysts for hydrolysis of cellobiose and cellulose. Green Chem. 2009, 11, 1627-1632. [CrossRef]

14. Kobayashi, H.; Komanoya, T.; Hara, K.; Fukuoka, A. Water-Tolerant Mesoporous-Carbon-Supported Ruthenium Catalysts for the Hydrolysis of Cellulose to Glucose. ChemSusChem 2010, 3, 440-443. [CrossRef] [PubMed]

15. Pang, J.; Wang, A.; Zheng, M.; Zhang, T. Hydrolysis of cellulose into glucose over carbons sulfonated at elevated temperatures. Chem. Commun. 2010, 46, 6935-6937. [CrossRef] [PubMed]

16. Lai, D.; Deng, L.; Li, J.; Liao, B.; Guo, Q.; Fu, Y. Hydrolysis of cellulose into glucose by magnetic solid acid. ChemSusChem 2011, 4, 55-58. [CrossRef] [PubMed]

17. Cai, H.; Li, C.; Wang, A.; Xu, G.; Zhang, T. Zeolite-promoted hydrolysis of cellulose in ionic liquid, insight into the mutual behavior of zeolite, cellulose and ionic liquid. Appl. Catal. B 2012, 123, 333-338. [CrossRef]

18. Abou-Yousef, H.; Hassan, E.B. A novel approach to enhance the activity of H-form zeolite catalyst for production of hydroxymethylfurfural from cellulose. J. Ind. Eng. Chem. 2014, 20, 1952-1957. [CrossRef]

19. Zhang, Z.; Zhao, Z.K. Solid acid and microwave-assisted hydrolysis of cellulose in ionic liquid. Carbohydr. Res. 2009, 344, 2069-2072. [CrossRef] [PubMed]

20. Perego, C.; Bosetti, A. Biomass to fuels: The role of zeolite and mesoporous materials. Microporous Mesoporous Mater. 2011, 144, 28-39. [CrossRef]

21. Onda, A.; Ochi, T.; Yanagisawa, K. Selective hydrolysis of cellulose into glucose over solid acid catalysts. Green Chem. 2008, 10, 1033-1037. [CrossRef] 
22. Tao, Y.; Kanoh, H.; Abrams, L.; Kaneko, K. Mesopore-modified zeolites: Preparation, characterization, and applications. Chem. Rev. 2006, 106, 896-910. [CrossRef] [PubMed]

23. Li, J.; Li, X.; Zhou, G.; Wang, W.; Wang, C.; Komarneni, S.; Wang, Y. Catalytic fast pyrolysis of biomass with mesoporous ZSM-5 zeolites prepared by desilication with NaOH solutions. Appl. Catal. 2014, 470, 115-122. [CrossRef]

24. Nandiwale, K.Y.; Galande, N.D.; Thakur, P.; Sawant, S.D.; Zambre, V.P.; Bokade, V.V. One-Pot Synthesis of 5-Hydroxymethylfurfural by Cellulose Hydrolysis over Highly Active Bimodal Micro/Mesoporous H-ZSM-5 Catalyst. ACS Sustain. Chem. Eng. 2014, 2, 1928-1932. [CrossRef]

25. Zhou, L.; Shi, M.; Cai, Q.; Wu, L.; Hu, X.; Yang, X.; Chen, C.; Xu, J. Hydrolysis of hemicellulose catalyzed by hierarchical H-USY zeolites-The role of acidity and pore structure. Microporous Mesoporous Mater. 2013, 169, 54-59. [CrossRef]

26. Zhou, L.; Liu, Z.; Shi, M.; Du, S.; Su, Y.; Yang, X.; Xu, J. Sulfonated hierarchical H-USY zeolite for efficient hydrolysis of hemicellulose/cellulose. Carbohydr. Polym. 2013, 98, 146-151. [CrossRef] [PubMed]

27. Miller, G.L. Use of dinitrosalicylic acid reagent for determination of reducing sugar. Anal. Chem. 1959, 31, 426-428. [CrossRef]

28. Ogura, M.; Shinomiya, S.; Tateno, J.; Nara, Y.; Nomura, M.; Kikuchi, E.; Matsukata, M. Alkali-treatment technique-New method for modification of structural and acid-catalytic properties of ZSM-5 zeolites. Appl. Catal. 2001, 219, 33-43. [CrossRef]

29. Tao, Y.; Kanoh, H.; Kaneko, K. Developments and structures of mesopores in alkaline-treated ZSM-5 zeolites. Adsorption 2006, 12, 309-316. [CrossRef]

30. Groen, J.C.; Jansen, J.C.; Moulijn, J.A.; Pérez-Ramírez, J. Optimal aluminum-assisted mesoporosity development in MFI zeolites by desilication. J. Phys. Chem. B 2004, 108, 13062-13065. [CrossRef]

31. Su, L.; Liu, L.; Zhuang, J.; Wang, H.; Li, Y.; Shen, W.; Xu, Y.; Bao, X. Creating mesopores in ZSM-5 zeolite by alkali treatment: A new way to enhance the catalytic performance of methane dehydroaromatization on Mo/HZSM-5 catalysts. Catal. Lett. 2003, 91, 155-167. [CrossRef]

32. Salman, N.; Rüscher, C.H.; Buhl, J.C.; Lutz, W.; Toufar, H.; Stöcker, M. Effect of temperature and time in the hydrothermal treatment of HY zeolite. Microporous Mesoporous Mater. 2006, 90, 339-346. [CrossRef]

33. Swatloski, R.P.; Spear, S.K.; Holbrey, J.D.; Rogers, R.D. Dissolution of cellose with ionic liquids. J. Am. Chem. Soc. 2002, 124, 4974-4975. [CrossRef] [PubMed]

34. Zhu, S.; Wu, Y.; Chen, Q.; Yu, Z.; Wang, C.; Jin, S.; Ding, Y.; Wu, G. Dissolution of cellulose with ionic liquids and its application: A mini-review. Green Chem. 2006, 8, 325-327. [CrossRef]

35. Zhang, B.; Li, X.; Wu, Q.; Zhang, C.; Yu, Y.; Lan, M.; Wei, X.; Ying, Z.; Liu, T.; Liang, G.; Zhao, F. Synthesis of $\mathrm{Ni} /$ mesoporous ZSM-5 for direct catalytic conversion of cellulose to hexitols: Modulating the pore structure and acidic sites via a nanocrystalline cellulose template. Green Chem. 2016, 18, 3315-3323. [CrossRef]

36. Rinaldi, R.; Meine, N.; vom Stein, J.; Palkovits, R.; Schüth, F. Which controls the depolymerization of cellulose in ionic liquids: The solid acid catalyst or cellulose? ChemSusChem 2010, 3, 266-276. [CrossRef] [PubMed]

37. Tian, F.; Wu, Y.; Shen, Q.; Li, X.; Chen, Y.; Meng, C. Effect of Si/Al ratio on mesopore formation for zeolite beta via $\mathrm{NaOH}$ treatment and the catalytic performance in $\alpha$-pinene isomerization and benzoylation of naphthalene. Microporous Mesoporous Mater. 2013, 173, 129-138. [CrossRef]

38. Milina, M.; Mitchell, S.; Michels, N.L.; Kenvin, J.; Pérez-Ramírez, J. Interdependence between porosity, acidity, and catalytic performance in hierarchical ZSM-5 zeolites prepared by post-synthetic modification. J. Catal. 2013, 308, 398-407. [CrossRef]

39. Ramli, N.A.S.; Amin, N.A.S. Catalytic hydrolysis of cellulose and oil palm biomass in ionic liquid to reducing sugar for levulinic acid production. Fuel Process. Technol. 2014, 128, 490-498. [CrossRef]

40. Hu, L.; Wu, Z.; Xu, J.; Sun, Y.; Lin, L.; Liu, S. Zeolite-promoted transformation of glucose into 5-hydroxymethylfurfural in ionic liquid. Chem. Eng. J. 2014, 244, 137-144. [CrossRef]

Sample Availability: Samples of the alkaline-treated ZSM-5 and the products are available from the authors. 